\title{
Differential modulation of CXCR4 and CD40 protein levels by skin sensitizers and irritants in the FSDC cell line
}

\author{
Bruno Miguel Nevesa,b, Maria Teresa Cruza,b, , Vera Francisco b, Margarida Gonc,alo c, \\ Am'erico Figueiredo c, Carlos B. Duarte b, Maria Celeste Lopes a,b \\ a Faculdade de Farm 'cia, Universidade de Coimbra, Rua do Norte, Coimbra, Portugal \\ b Centro de Neuroci ^ncias e Biologia Celular, Universidade de Coimbra, Coimbra, Portugal \\ c Faculdade de Medicina (Servi , o de Dermatologia), Hospital da Universidade de Coimbra, Coimbra, Portugal \\ Received 12 October 2007; received in revised form 12 December 2007; accepted 17 December 2007 \\ Available online 24 December 2007
}

\begin{abstract}
The development of non-animal methods for skin sensitization testing is an urgent challenge. Some of the most promising in vitro approaches are based on the analysis of phenotypical and functional modifications induced by sensitizers in dendritic cell models. In this work, we evaluated, for the first time, a fetal skin-derived dendritic cell line (FSDC) as a model to discriminate between sensitizers and irritants, through analysis of their effects on CD40 and CXCR4 protein expression. The chemicals concentrations were chosen based on a slight cytotoxicity effect (up to $15 \%$ ).Protein levels were evaluated by Western blot and immunocytochemistry, after stimulation with the skin sensitizers 2,4-dinitrofluorobenzene

(DNFB), 1,4-phenylenediamine (PPD) and nickel sulphate ( $\mathrm{NiSO}_{4}$ ), the non-sensitizer 2,4-dichloronitrobenzene (DCNB), and the irritants sodium dodecyl sulphate (SDS) and benzalkonium chloride (BC). All sensitizers tested increased CD40 and CXCR4 levels. In contrast, irritants decreased both proteins levels, with a more pronounced effect on CXCR4. In agreement with these results, dendritic cells derived from human peripheral blood monocytes-derived dendritic cells (MoDC) showed a similar response pattern to the skin sensitizer and irritant tested, PPD and SDS, respectively. In conclusion, evaluation of CD40 and CXCR4 proteins in chemical-treated FSDC may represent a useful tool in a future in vitro test for sensitizing assessment.

(c) 2007 Elsevier Ireland Ltd. All rights reserved.
\end{abstract}

Keywords: In vitro sensitization test; FSDC cell line; CXCR4; CD40

\section{Introduction}

Allergic contact dermatitis (ACD), a delayed-type hypersensitivity reaction caused by contact of the skin with low molecular weight reactive chemicals (haptens), is a common occupational and environmental health problem, affecting approximately $1 \%$ of the general population (Divkovic et al., 2005; Ryan et al., 2005).Currently, the assessment of the sensitizing potential of chemicals is mainly based on animal tests, such as the local lymph node assay (LLNA) (Kimber et al., 1995), the guinea pig maximization test (GPMT) (Magnusson and Kligman, 1969) and the Buehler test (Buehler, 1965). However, the publication of the 7th Amendment to the European Cosmetics Directive raised

\footnotetext{
Corresponding author. Tel.: +351239 480203; fax: +351239480217.

E-mail address: trosete@ff.uc.pt (M.T. Cruz).
}

the need of developing alternative in vitro/in silico methods (EC, 2003; Basketter et al., 2007).

Some of the most promising in vitro approaches explore the interactions of contact allergens with dendritic cells (DC), which are crucial in the induction phase of ACD (Ryan et al., 2005).Langerhans cells (LC), the main antigen-presenting cells of the skin, typify the sentinel role of immature DC, translating changes in their local microenvironment into specific immune responses. Following an encounter with an haptenized-peptide, LC become activated, leave the skin, migrate via the afferent lymphatics to the draining lymph nodes and differentiate into fully mature DC, able to effectively present antigens to na" ve T-cells. During maturation, LC experiment morphological, functional and phenotypical changes, including up-regulation of class II MHC molecules, costimulatory molecules such as CD83, CD80, CD86, CD40 and the adhesive molecules CD54 and CD58 (Banchereau et al., 2000). These changes were early 
seen as opportunities to correlate the sensitizing potential of chemicals with their ability to activate DC, and have been explored by several groups in the last years (reviewed by Ryan et al., 2005).

Since LC constitute only 1-3\% of all epidermal cells and no LC line has been established until now, DC derived from CD34+ progenitor cells (Strunk et al., 1996), or from peripheral blood mononuclear cells (PBMC) (Sallusto and Lanzavecchia, 1994)have been used as DC surrogates. These DC-like cells have been used to evaluate the effect of sensitizers through measure ment of the surface expression of HLA-DR, CD54, CD83, CD86 (Rougier et al., 2000; Tuschl et al., 2000; Hulette et al., 2002; Staquet et al., 2004), production of cytokines or chemokines (Aiba et al., 1997; Ebner et al., 1998; Coutant et al., 1999; Jugde et al., 2005), and through evaluation of tyrosine phosphorylation or activation of the MAPK signalling pathways (Becker et al., 1997; Kuhn et al., 1998; Arrighi et al., 2001). Another recent approach, focused on holistic transcript profiling of DC exposed to sensitizers, in which total mRNA profile was examined, pro vided new information about genome-wide changes that could be helpful in the identification of novel biomarkers of DC acti vation (Ryan et al., 2004; Gildea et al., 2006; Schoeters et al., 2006).

To circumvent the inexistence of a standardized protocol for generating DC-like cells and the inherent variability of immature DC obtained from human donors, several groups have tried to use human myeloid cell lines, namely THP-1 (Ashikaga et al., 2002; Hulette et al., 2002; Yoshida et al., 2003), U937 (Python et al., 2007), MUTZ-3 (Azam et al., 2006), or the murine XS52 cell line (Neisius et al., 1999; Herouet et al., 2000), as tools for the in vitro identification of contact sensitizers.

However, currently, there are no validated in vitro methods for the identification of skin sensitizing chemicals, and basic immunological research is still necessary to identify new can didates to be tested for this purpose. Some of the promising parameters to be evaluated are intracellular signalling pathways activated by skin sensitizers, the modulation of the plasma mem brane expression of proteins and cell-cell signalling molecules, and also changes in the antigen uptake process in DC (Basketter et al., 2007).

In this context, the aim of the present study was to evaluate the effect of different contact sensitizers, namely 2,4-dinitrofluorobenzene (DNFB), 1,4-phenylenediamine (PPD) and nickel sulphate (NiSO4), the non-sensitizer 2,4 dichloronitrofluorobenzene (DCNB), and the irritants sodium dodecyl sulphate (SDS) and benzalkonium chloride (BC), on the protein levels of the chemokine receptor CXCR4 and the costimulatory molecule CD40, in DC. As experimental model of DC we used a mouse fetal skin-derived dendritic cell line (FSDC), which has been previously used as a model of immature DC (Mann et al., 2002; Egan et al., 2004). This cell line has morphological, phenotypical and functional

characteristics of Langerhans cells (Girolomoni et al., 1995), and, in contrast to other DC-like cell lines, is cultured in the absence of exogenous growth factors. In addition, the results obtained in this cell line were confirmed on human peripheral blood monocytederived dendritic cells (MoDC).

\section{Materials and methods}

\subsection{Materials}

DNFB and DCNB were obtained from Sigma-Aldrich Qu'mica (Madrid, Spain), NiSO4 and BC were purchased from Sigma Chemical Co. (Madrid, Spain) and PPD from Aldrich Chemical Co. (Madrid, Spain). Lipopolysac charide (LPS) from Escherichia coli (serotype 026:B6) was obtained from Sigma Chemical Co. (St. Louis, MO, USA). Fetal calf serum and trypsin were purchased from Gibco (Paisley, UK), GM-CSF and IL-4 were from PeproTech (London, UK), and the protease inhibitor cocktail and the mono clonal anti-actin antibody were obtained from Roche (Carnaxide, Portugal). The rabbit polyclonal antibody against CXCR4 was purchased from Abcam (Cambridge,UK) and the anti-CD40 antibody was from R\&D Systems (Min neapolis, MN). Lymphoprep was from Axis-Shield (Oslo, Norway) and the MACS colloidal supermagnetic microbeads conjugated with anti-human CD14 monoclonal antibody (CD14 microbeads) were purchased from Miltenyi Biotec Inc. (Bergisch Gladbach, Germany). The Lab-Tek Chamber Slides were pur chased from Nunc GmbH \& Co. KG (Wiesbaden, Germany) and the Vectashield mounting medium was from Vector, Inc. (Burlingame, CA, U.S.A.) The alkaline phosphatase-linked secondary antibodies and the enhanced chemifluorescence (ECF) reagent were obtained from GE Healthcare (Carnaxide, Portugal), and the polyvinylidene difluoride (PVDF) membranes were from Millipore Corpora tion (Bedford, MA). All other reagents were from Sigma Chemical Co. (Madrid, Spain).

\subsection{Generation of peripheral monocyte-derived DC (MoDC)}

Peripheral blood mononuclear cells were obtained from fresh EDTA treated blood of healthy human donors (after their informed consent), using Lym phoprep density gradient centrifugation. Briefly, blood was diluted with equal parts of PBS and $30 \mathrm{ml}$ samples were seeded in $50 \mathrm{ml}$ Falcon tubes contain ing $15 \mathrm{ml}$ of Lymphoprep. The tubes were centrifuged at $600 \times \mathrm{g}$, for $30 \mathrm{~min}$ at $20 \cdot \mathrm{C}$, and the mononuclear fraction was collected and washed with PBS supplemented with $0.5 \%$ FCS and 2 mM EDTA (MACS buffer). After count ing, PBMC were resuspended in the appropriate volume of MACS buffer and incubated with CD14 microbeads, for $20 \mathrm{~min}$ at $4{ }^{\circ} \mathrm{C}$. After washing, CD14+ cells were separated by positive selection in a magnetic cell separator column. CD14+ monocytes were cultured for 7 days, in RPMI-1640 medium supple mented with $10 \%$ (v/v) fetal calf serum, $100 \mathrm{~g} / \mathrm{ml}$ streptomycin, $100 \mathrm{U} / \mathrm{ml}$ penicillin, $800 \mathrm{U} / \mathrm{ml} \mathrm{IL-4}$ and $1000 \mathrm{U} / \mathrm{ml} \mathrm{GM}-\mathrm{CSF}$, in a humidified incubator with $5 \% \mathrm{CO}_{2} / 95 \%$ air, at $37 \cdot \mathrm{C}$. One half of the culture medium was replaced on day 3 and day 5 , by fresh medium containing the same cytokines concentra tions. The phenotype of these cells at day 7 is consistent with an immature DC phenotype: HLA-DR+, CD1a+, CD83-, CD80low and CD86low (Hulette et al., 2002).

\subsection{Culture of FSDC}

The fetal mouse skin-derived dendritic cell line, kindly supplied by Dr. G. Girolomoni (Laboratory of Immunology, Instituto Dermopatico dell'Imacolata, IRCCS, Rome, Italy), is a skin dendritic cell precursor with antigen presenting capacity. This cell line was previously characterised and had a surface phe notype consistent with a Langerhans cell progenitor (H-2d.b+, I-Ad.b+, CD54+, MHCII $+, \mathrm{MHCI}+, \mathrm{CD} 11 \mathrm{c}+, \mathrm{CD} 11 \mathrm{~b}+, \mathrm{B} 7.2+, \mathrm{CD} 44+\mathrm{B} 220, \mathrm{CD} 3)$ (Girolomoni et al., 1995), being this phenotype actually confirmed in our lab for the most important of these surface markers (data not shown). The FSDC did not require exogenous growth factors for their continued proliferation when cultured in serum-containing medium, having a doubling time of about $48 \mathrm{~h}$. The cells were used after reaching 70-80\% confluence, which occurs approximately every 3days. After 45 passages the cells were discarded. FSDC are adherent and present a morphology consistent with a DC type, having an irregular shape and many surface projections arising from the cell. The cells were cultured in endotoxin-free Iscove's Modified Dulbecco's Medium (IMDM), supplemented with $10 \%(\mathrm{v} / \mathrm{v})$ fetal calf serum, $1 \%(\mathrm{w} / \mathrm{v})$ glutamine, $3.02 \mathrm{~g} / 1$ sodium bicarbon ate, $100 \mathrm{~g} / \mathrm{ml}$ streptomycin and $100 \mathrm{U} / \mathrm{ml}$ penicillin, in a humidified incubator with $5 \% \mathrm{CO}_{2} / 95 \%$ air, at 37 . C. 


\subsection{Determination of FSDC viability by the MTT assay}

FSDC were exposed, for $24 \mathrm{~h}$, to the tested chemicals in a dose response experiment and analyzed for viability by the reduction of the tetrazolium bromide salt, 3-(4,5-dimethylthiazol-2-yl)-2,5-diphenyl tetrazolium bromide (MTT) (Mosmann, 1983). Briefly, FSDC were plated at $0.2 \times 106$ cells/well in 48 -well plates in a final IMDM volume of 4001 and stock solutions of chemi

cals were added to obtain the different final in-well concentrations studied. After $23 \mathrm{~h}$ exposure, 401 of MTT solution $(5 \mathrm{mg} / \mathrm{ml})$ was added to each well and cells were further incubated at $37 \cdot \mathrm{C}$ for $1 \mathrm{~h}$. Finally, the supernatants were discarded and 3001 of acidic isopropanol was added to the cells. Formazan quantification

was performed using an automatic plate reader (SLT, Austria) at $570 \mathrm{~nm}$, with a reference wavelength of $620 \mathrm{~nm}$.

\subsection{Chemical treatment}

At day 7 of culture, immature MoDC were harvested by centrifugation, resus pended in fresh cytokines containing medium and plated at $0.3 \times 106$ cells/well in 24-well plates. FSDC were collected by trypsinization, resuspended in fresh IMDM medium and plated at $2 \times 106$ cells/well in six-well microplates, or at $125 \times 103$ cells $/ \mathrm{cm}_{2}$ in Lab-Tek Chamber Slides, for Western blot analysis and immunocytochemistry, respectively. The cells were incubated overnight, prior to chemical exposure. After this period, stock solutions were added to obtain a final in-well concentration of $5 \mathrm{~g} / \mathrm{ml} \mathrm{LPS}, 1 \mathrm{~g} / \mathrm{ml}$ DNFB, $50 \mathrm{~g} / \mathrm{ml} \mathrm{PPD}, 50 \mathrm{~g} / \mathrm{ml}$ $\mathrm{NiSO}_{4}, 1 \mathrm{~g} / \mathrm{ml}$ DCNB, $50 \mathrm{~g} / \mathrm{ml}$ SDS and $1 \mathrm{~g} / \mathrm{ml} \mathrm{BC}$. SDS, BC, PPD and NiSO4 were dissolved in PBS, while DNFB and DCNB were first solubilised in dimethyl sulphoxide and subsequent dilutions were performed in PBS. The final concentration of dimethyl sulphoxide never exceeded $0.01 \%(\mathrm{v} / \mathrm{v})$, and was without effect on cell viability and on CXCR4 and CD40 expression (data not shown). Control experiments consisted in non-treated cells.

\subsection{Cell lysate preparation}

To prepare total cell lysates for Western blot analysis, after $24 \mathrm{~h}$ of chemical stimulation, cells were washed with ice-cold PBS and harvested in a sonication buffer containing $0.25 \quad \mathrm{M}$ sucrose, $\quad 10 \quad \mathrm{mM} \quad$ Tris- $\mathrm{HCl} \quad(\mathrm{pH} \quad 7.5), \quad 1 \quad \mathrm{mM}$ ethylenediaminetetraacetic acid, $1 \mathrm{mM}$ dithiothreitol, $10 \mathrm{mM}$ sodium fluoride and a protease inhibitor cocktail. The lysates were then incubated on ice, for $30 \mathrm{~min}$, and sonicated four times, for $4 \mathrm{~s}$ at $40 \mathrm{~m}$ in a Vibra Cell sonicator (Sonics \&

Material INC), to disrupt the cells. Protein concentration was determined using the bicinchoninic acid method and the cell lysates were denatured at $100 \cdot \mathrm{C}$, for $7 \mathrm{~min}$, in sample buffer $(0.125 \mathrm{mM}$ Tris $\mathrm{pH} 6.8 ; 2 \%$ (w/v) SDS; $100 \mathrm{mM}$ DTT; $10 \%$ glycerol and bromophenol blue).

\subsection{Western blot analysis}

Western blot was performed to evaluate CXCR4 and CD40 protein levels. Briefly, each gel was loaded always with the same amount of protein which was 60 or 80 (depending on the amount of protein available). The proteins were electrophoretically separated on a $12 \%$ (v/v) SDS-PAGE, and transferred to a PVDF membrane. The membranes were blocked with $5 \%(\mathrm{w} / \mathrm{v})$ fat-free dry milk in Tris-buffered saline containing $0.1 \%(\mathrm{v} / \mathrm{v})$ Tween 20 (TBS-T), for $1 \mathrm{~h}$ at room temperature. Blots were then incubated, for $1 \mathrm{~h}$ at room temperature, with a rabbit polyclonal anti-CXCR4 antibody $(1: 1000)$ or a rat monoclonal anti-mouse CD40 antibody (1:500), washed for $25 \mathrm{~min}$ with $1 \%(\mathrm{w} / \mathrm{v})$ fat free dry milk in TBS-T, and incubated, for $1 \mathrm{~h}$, at room temperature, with a alkaline phosphatase-conjugated anti-rabbit antibody $(1: 20,000)$, or a alkaline phosphatase-conjugated anti-rat antibody $(1: 10,000)$, respectively. The immune complexes were detected by membrane exposure to the ECF reagent, dur ing $8 \mathrm{~min}$, followed by scanning for blue excited fluorescence on the Storm 860 (GE Healthcare). The generated signals were analyzed using the Image Quant TL software. To ensure that there were similar amounts of protein in each sample, the membranes were stripped, reprobed with a monoclonal anti-actin antibody $(1: 10,000)$, and developed with an alkaline phosphatase conjugated anti-mouse antibody $(1: 20,000)$, by enhanced chemifluo rescence.

\subsection{Immunocytochemistry assay}

The effect of skin sensitizers and irritants on the expression of the CXCR4 protein was also evaluated by immunocytochemistry analysis. FSDC, cultured in Lab-Tek Chamber Slides and stimulated as described above, were washed with ice-cold PBS and fixed and permeabilized with cold methanol:acetone (1:1), for $10 \mathrm{~min}$. The cells were then incubated for $1 \mathrm{~h}$ at $4 \cdot \mathrm{C}$, with a rabbit poly clonal anti-CXCR4 antibody (1:200), washed three times with PBS, for $5 \mathrm{~min}$, and incubated, for $1 \mathrm{~h}$ at room temperature, with Alexa 488-conjugated goat anti-rabbit antibody (1:500). After a new washing step, the cells were mounted with Vectashield mounting medium to reduce the photobleaching. Negative con trol experiments consisted of processing the same preparations as described above, except for the omission of the primary antibody, resulting in weak non specific staining. Fluorescence labelling was visualized using a Zeiss Axiovert 200microscope, and images captured with a coupled AxioCamHR camera. In each experiment, the optimal acquisition parameters were defined for the control cells and then maintained for all the other conditions within the same experiment.

\subsection{Data analysis}

The results are presented as mean \pm S.E. of the indicated number of experiments, and the means were statistically compared using the One-Way ANOVA test, with a Dunnett's post-test. The significance level was $* \mathrm{p}<0.05$, $* *$ $\mathrm{p}<0.01$.

\section{Results}

\subsection{Effect of skin sensitizers and irritants on the viability of FSDC: determination of optimal chemicals concentrations}

Since it has been shown that cytotoxicity may play a relevant role in DC activation (Hulette et al., 2005) we considered as opti mal chemicals concentrations those that induced up to $10-15 \%$ cytotoxicity. Considering this criterion, the selected concentra tions were $1 \mathrm{~g} / \mathrm{ml}$ DNFB, $50 \mathrm{~g} / \mathrm{ml}$ PPD, $50 \mathrm{~g} / \mathrm{ml} \mathrm{NiSO} 4$, $1 \mathrm{~g} / \mathrm{ml}$ DCNB, $50 \mathrm{~g} / \mathrm{ml} \mathrm{SDS}$ and $1 \mathrm{~g} / \mathrm{ml} \mathrm{BC} \mathrm{(Fig.} \mathrm{1).} \mathrm{As} \mathrm{shown} \mathrm{in}$ Fig. 1, increasing concentrations of the allergen PPD caused an apparent increase of cell viability, but in fact this is due to a direct interaction of PPD with the reagent MTT, which causes an increase in the absorbance values. Therefore,
Fig. 1. Effects of chemicals on FSDC viability: determination of optimal con centrations. FSDC were incubated, for $24 \mathrm{~h}$, In culture medium in the absence (control), or in the presence of different concentrations of the indicated chem icals. After this period, the cell viability was assessed by the MTT assay, as described in "Section 2". Results are expressed as a percentage of MTT reduc tion by control cells, maintained in culture medium. The horizontal black dashed line indicates the limit of $85 \%$ of control (viability criterion). Each value repre sents the mean \pm S.E. from three independent experiments, each one performed in duplicate. 
for this sensitizer we accessed the cell viability by the Trypan Blue exclusion assay (data not shown).

\subsection{Effect of skin sensitizers and irritants on CXCR4 protein levels in FSDC}

After FSDC exposure, during 24h, to three skin sen sitizers and two irritants, the changes in CXCR4 protein levels were determined by Western blot. As shown in Fig. 2 (lanes 2, 3 and 4), CXCR4 protein levels were significantly increased after cell treatment with all the skin sensitizers tested, namely DNFB, PPD and NiSO4, by $44.4 \pm 7.1 \%, 54.7 \pm 3.6 \%$ and $18.1 \pm 1.8 \%$, respectively. In contrast, exposure to irri tants resulted in a marked down-regulation of CXCR4, by $65.0 \pm 6.8 \%$ or $69.2 \pm 5.8 \%$, for SDS and BC, respectively. When the cells were incubated with the non-sensitizer DCNB no effect was observed on CXCR4 protein levels (Fig. 2, lane $5)$.

Immunofluorescence microscopy experiments confirmed these results and showed an up-regulation of CXCR4 induced by all the sensitizers tested (Fig. 2c). Interestingly, these increases in CXCR4 immunoreactivity were predominantly observed at an intracellular level. Immunofluorescence labelling of FSDC cells also confirmed that the non-sensitizer DCNB had no significant effect on CXCR4 protein levels.
Table 1

Modulation of CXCR4 protein levels by LPS, PPD and SDS in human monocyte derived dendritic cells

\begin{tabular}{llll} 
& LPS & PPD & SDS \\
\hline Donor 1 & $\uparrow \uparrow$ & $\uparrow$ & $\downarrow$ \\
Donor 2 & $\uparrow$ & $\uparrow \uparrow$ & $\downarrow \downarrow$ \\
Donor 3 & $\uparrow \uparrow$ & $\uparrow \uparrow \uparrow$ & $\uparrow$
\end{tabular}

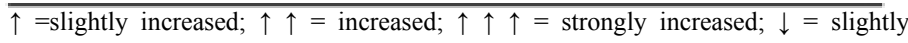
decreased; $\downarrow \downarrow=$ decreased

\subsection{Effect of LPS, PPD and SDS on CXCR4 protein levels in MoDC}

The effect of sensitizers and irritants on CXCR4 protein levels in FSDC was confirmed in monocyte-derived dendritic cells. The cells were stimulated with the sensitizer PPD or with the irritant SDS, and lipopolysaccharide was used as a positive control since it is known to induce MoDC activation and up-regulation of maturation markers (Verhasselt et al., 1997; Hulette et al., 2002).Each experiment was conducted with cells isolated from blood of a single donor, differentiated in IL-4 and GM-CSF containing medium for 7 days, and subsequently exposed to stimuli for $24 \mathrm{~h}$. CXCR 4 protein was then quantified by Western blot analysis. Exposure of cells to the sensitizer PPD resulted in increased levels of the receptor in all experiments, while treat

Fig. 2. Skin sensitizers and irritants have opposite effects on CXCR4 protein levels in FSDC. (a) FSDC cells $(2 \times 106$ cells $)$ were incubated, for $24 \mathrm{~h}$, in culture medium in the absence (control, lane 1) or in the presence of $1 \mathrm{~g} / \mathrm{ml} \mathrm{DNFB,} 50 \mathrm{~g} / \mathrm{ml} \mathrm{PPD,} 50 \mathrm{~g} / \mathrm{ml} \mathrm{NiSO} 4,1 \mathrm{~g} / \mathrm{ml} \mathrm{DCNB}, 50 \mathrm{~g} / \mathrm{ml} \mathrm{SDS}$ or $1 \mathrm{~g} / \mathrm{ml} \mathrm{BC}$. Equal amounts of protein, obtained from total cell extracts, were loaded on 12\% SDS-polyacrylamide gels, subjected to electophoresis and electrotransferred to PVDF membranes. Immunoblotting of CXCR4 protein was performed using an anti-CXCR4 antibody, as described in "Section 2". To ensure that there were similar amounts of protein in each sample, the membranes were stripped, reprobed with a monoclonal anti-actin antibody $(1: 10,000)$, and developed with an alkaline phosphatase conjugated anti-mouse antibody (1:20,000). The blot shown is representative of nine independent experiments yielding similar results. (b) The optical densities of the bands were obtained by scanning the membranes in a fluorescence scanner, and then analysed with the ImageQuant TL Software. The results were expressed as $\%$ of CXCR4 expression relatively to control. Each value represents the mean \pm S.E. from nine independent experiments $(* \mathrm{p}<0.05 ; * * \mathrm{p}<0.01$ as compared to the control). (c) Immunofluorescence analysis of the effect of skin sensitizers and irritants on CXCR4 protein levels. FSDC cells (125 $\times 103$ cells/cm 2$)$ were incubated on Lab-Tek Chamber Slides, under the same conditions as described for Western blot analysis. Immunostaining was performed as described in "Section 2". The images were acquired with an AxioCamHR camera, coupled to a Zeiss Axiovert 200 microscope and analyzed with AxioVision v.4.5 software. The images shown are representative of three individual experiments yielding similar results. Scale bar $=50 \mathrm{~m}$. 
Fig. 2. (Continued)

ment with the irritant SDS caused a reduction in two of the three assays (Table 1). This response pattern (Fig. 3) is similar to the one obtained in FSDC, indicating that only the sensitizer tested is able to increase CXCR4 expression in both cell models. Accordingly, LPS-matured MoDC also presented increased lev els of CXCR4 protein in all the experiments performed. In spite of the reproducibility of the MoDC responses, their magnitudes varied considerably between experiments. Therefore, the results were not statistically treated and are presented in a qualitative form. 
Fig. 3. MoDC exposed to the sensitizer PPD and the irritant SDS show a CXCR4 response pattern similar to that one obtained in FSDC. (a) MoDC were obtained by culturing human monocytes in GM-CSF and IL-4-supplemented culture medium, for 7 days, as described in "Section 2". Cells $(0.3 \times 106$ cells $)$ were then incubated, for $24 \mathrm{~h}$, in culture medium, in the absence (control, lane 1) or in the presence of $5 \mathrm{~g} / \mathrm{ml} \mathrm{LPS}, 50$ $\mathrm{g} / \mathrm{ml} \mathrm{PPD}$, or $50 \mathrm{~g} / \mathrm{ml} \mathrm{SDS}$. Equal amounts of protein, obtained from total cell extracts, were loaded on $12 \%$ SDSpolyacrylamide gels, subjected to electophoresis and electrotransferred to PVDF membranes. Immunoblotting of CXCR4 protein was performed using an antiCXCR4 antibody. To ensure that there were similar amounts of protein in each sample, the membranes were stripped, reprobed with a monoclonal antiactin antibody $(1: 10,000)$, and developed with an alkaline phosphatase-conjugated antimouse antibody $(1: 20,000)$. The blot shown is representative of the CXCR4 response pattern to sensitizers and irritants in three independent experiments. (b) The optical densities of the bands were obtained by scanning the membranes in a fluorescence scanner, and then analysed with the ImageQuant TL Software. The results were qualitatively expressed in Table 1 as increases or decreases of

CXCR4 protein levels relatively to the control cells.

\subsection{Effect of skin sensitizers and irritants on CD40 protein levels in FSDC}

Stimulation of cells with the skin sensitizers DNFB and PPD significantly increased the CD40 protein levels, by $25.7 \pm 3.4 \%$ and $47.2 \pm 12.4 \%$, respectively, whereas exposure to NiSO 4 resulted in a non-statistically significant increase of $13.1 \pm 2.0 \%$ (Fig. 4, lanes 2, 3 and 4). Similarly to CXCR4, cell exposure to $\mathrm{NiSO} 4$ resulted in a smaller but very reproducible increase in CD40 protein levels. In contrast to skin sensitizers, both irritants tested, SDS and BC, decreased CD40 levels by $21.6 \pm 2.2 \%$ and $42.8 \pm 4.5 \%$, respectively (Fig. 4, lanes 6 and 7). Again, no effect was found after treatment with the non-sensitizer DCNB (Fig. 4, lane 5).

\section{Discussion}

The development of in vitro methods for predicting the sen sitizing potential of new chemicals is of major importance for the reduction of animal testing and the maintenance of product safety. Several approaches, with different levels of complex ity, have been described. Some of the most promising assays are based on the use of dendritic-like cell cultures in order to reconstitute the maturation process of Langerhans cells after exposure to sensitizers, by monitoring activation markers such as CD86, CD83, CD40 and CD54. However, owing to the vari ability reported in many of the surface markers studied to date, it is appropriate to consider alternative experimental strategies, including the use of other DC models and assessment of new possible markers.

In the present study, the potential use of the FSDC cell line to discriminate between skin sensitizers, irritants and nonsensitizers was evaluated for the first time, and the results obtained were compared with the response of human monocytederived dendritic cells. In contrast to other DC-cell lines, FSDC
Fig. 4. Skin sensitizers increase CD40 protein levels in FSDC. (a) FSDC cells $(2 \times 106$ cells) were incubated, for $24 \mathrm{~h}$, in culture medium in the absence (con trol, lane 1) or in the presence of $1 \mathrm{~g} / \mathrm{ml} \mathrm{DNFB,} 50 \mathrm{~g} / \mathrm{ml} \mathrm{PPD,} 50 \mathrm{~g} / \mathrm{ml}$ $\mathrm{NiSO} 4,1 \mathrm{~g} / \mathrm{ml}$ DCNB, $50 \mathrm{~g} / \mathrm{ml} \mathrm{SDS}$ or $1 \mathrm{~g} / \mathrm{ml} \mathrm{BC}$. Equal amounts of pro tein, obtained from total cell extracts, were loaded on $12 \%$ SDS-polyacrylamide gels, subjected to electophoresis and electrotransferred to PVDF membranes. Immunoblotting of CD40 protein was performed using an anti-CD40 antibody, as described in "Section 2". To ensure that there were similar amounts of pro tein in each sample, the membranes were stripped, reprobed with a monoclonal anti-actin antibody $(1: 10,000)$, and developed with an alkaline phosphatase conjugated anti-mouse antibody $(1: 20,000)$. The blot shown is representative of three independent experiments yielding similar results. (b) The optical densi ties of the bands were obtained by scanning the membranes in a fluorescence scanner, and then analysed with the ImageQuant TL Software. The results were expressed as \% of CD40 expression relatively to control. Each value represents the mean \pm S.E. from three independent experiments $(* p<0.05 ; * * p<0.01$ as compared to the control).

is cultured in the absence of exogenous growth factors and has a surface phenotype consistent with that of a Langerhans cell progenitor (H-2d.b+, I-Ad.b+ , CD54+, MHCII+, MHCI+, $\mathrm{CD} 11 \mathrm{c}+, \mathrm{CD} 11 \mathrm{~b}+, \mathrm{B} 7.2+, \mathrm{CD} 44+\mathrm{B} 220-, \mathrm{CD} 3-)$. This cell line has been previously used as an immature DC model (Mann et al., 2002; Egan et al., 2004). Upon treatment with cytokines, FSDC stimulate allogeneic or syngeneic T-cells in the primary mixed-leukocyte reaction and present haptens to primed T-cells in vitro. Moreover, FSDC derivatized with haptens and injected either intravenously or subcutaneously efficiently induce con tact sensitivity responses in na“ve syngeneic mice (Girolomoni et al., 1995). Using this cell line as an immature DC model, we analyzed the effect of the sensitizers DNFB, PPD and NiSO4, the non-sensitizer DCNB and the irritants SDS and BC, on the protein levels of the chemokine receptor CXCR4 and the co-stimulatory molecule CD40. The results were correlated with those obtained following exposure of human monocyte derived dendritic cells to LPS, to the sensitizer PPD and to the irritant SDS. Since the CD40 co-stimulatory molecule is a well-established MoDC maturation marker (Ryan et al., 2007) we focused our analysis on the CXCR4 receptor. Our results 
demonstrated that all of the skin sensitizers increased CXCR4 and CD40 protein levels in FSDC, in contrast with the effect of the irritants tested, which decreased both proteins. Further more, this CXCR4 response pattern was also observed in MoDC for the allergen (PPD) and irritant (SDS) tested in both cell models.

In this work we evaluated, for the first time, the potential utilization of CXCR4 as a biomarker to discriminate sensitiz ers from irritants. We observed that total CXCR4 protein levels were significantly increased after FSDC treatment with sensitiz ers, in contrast with the effect of irritants, which caused marked reductions (Fig. 2). Furthermore, this response pattern was also observed in MoDC, in which two of the three independent exper iments demonstrated a pattern very similar to that one obtained in FSDC (Fig. 3). MoDC exposure to LPS and PPD led to an up-regulation of the protein in all experiments, although with variable response magnitudes between donors (Table 1). This variability of MoDC responsiveness was previously reported in many studies and attributed to inter-individual variability and/or to the expression heterogeneity of the analysed molecules (Aiba et al., 1997; Lin et al., 1998; Pichowski et al., 2000). The observed similarity between the response patterns of the two cell models tested suggests that, as described by other authors for MoDC (Hulette et al., 2002; Jugde et al., 2005; Toebak et al., 2006),FSDC were also activated by sensitizers and not by irri tants. Another evidence that the CXCR4 receptor is modulated by the maturation state of DC was highlighted in recent works, which showed, through genomic analysis, that transcription of CXCR4 gene was slightly up-regulated on MoDC (Ryan et al., 2004)and CD34+ derived DC (Schoeters et al., 2006) after cells exposure to the contact sensitizers dinitrobenzenesulfonic acid and $\mathrm{NiSO} 4$, respectively.

Immunochemistry analysis of FSDC confirmed the Western blot results, and showed an up-regulation of CXCR4 induced by all the sensitizers tested, being this increases mainly observed at an intracellular level (Fig. 2c). These results are very interesting since in a flow cytometric study, significant decreases in CXCR4 surface expression were reported after FSDC exposure to DNFB, $\mathrm{NiSO} 4$ or the DC maturation stimulus LPS (Cruz et al., 2005). Moreover, in a work performed with MoDC, it was shown that, in spite of the up-regulation of CXCR4 mRNA in LPS-matured $\mathrm{DC}$, the receptor was not detectable at the cell surface and the cells did not respond to SDF-1 (Sallusto et al., 1998). However, when mature cells were washed and recultured in fresh medium without LPS, a recovery of the chemokine receptor was observed both in terms of surface expression and response to agonist. The authors discussed that this discrepancy between mRNA levels and surface receptor expression might be due to the produc tion of the CXCR4 ligand SDF-1 by maturing DC, resulting in desensitization of the CXCR4 receptors (Sallusto et al., 1998). Accordingly, the difference between the total CXCR4 protein levels and its surface expression in sensitizers-treated FSDC might be the result of a ligand-independent intracellular seques tration or of a desensitization process, in which matured FSDC produce SDF-1 that directly activates the receptor causing its internalization. These hypotheses are under current investigation in our lab.
The SDF-1-CXCR4 axis is commonly associated with cell trafficking, and the migratory capacities of DC are intimately related to their ability to switch the chemokine receptor reper toire according to their maturation state. Upon exposure to maturation stimuli, DC up-regulate the surface expression of CCR7 and CXCR4, gaining responsiveness to the chemokines CCL21, CCL19 and SDF-1, which drive their migration to the T-cell areas of draining lymph nodes (McColl, 2002). In contrast with CCR7, which has an established role in the migration of mature DC (Ohl et al., 2004; Humrich et al., 2006), the contri bution of CXCR4 is still far from being elucidated. However, from a physiopathologic point of view, CXCR4 may play a role in the initial phase of ACD. Given that SDF-1 is also expressed in inflamed tissues, the triggering of DC maturation by exoge nous stimuli, such sensitizers or LPS, causes an initial CXCR4 receptor internalization, allowing DC to leave the site of inflam mation. Subsequently, during migration, the receptor recycles back to the membrane and may act synergistically with CCR7 to drive DC to T-cell areas of secondary lymphoid organs. Since CXCR4 andCCR7 are expressed not only on mature DC but also on naive T-cells, this will favour the co-localization of these cells at sites where SDF-1, CCL19 and CCL21 are produced. In addi tion to this role in the migratory capacities of DC, CXCR4 could also be responsible for inhibition of apoptosis during the early phase of DC activation at the site of inflammation and/or during the migration of mature DC to the lymph nodes (Humrich et al., 2006). Accordingly, CXCR4 has recently been shown to be involved in DC survival (Kabashima et al., 2007).

In present work we also analysed the effect of three sensitiz ers and two irritants on the expression of CD40 co-stimulatory molecule in FSDC. We found that all the sensitizers tested increased CD40 protein levels, although with different magni tudes (Fig. 4). This may reflect the different sensitizing potency of the chemicals, since DNFB and PPD have stronger in vivo and in vitro activity than $\mathrm{NiSO} 4$. Accordingly, our previous works showed an up-regulation of this co-stimulatory molecule after treatment of the FSDC with the sensitizers DNFB and $\mathrm{NiSO} 4$, being the strongest effect induced by DNFB (Matos et al., 2005; Vital et al., 2004). Exposure of MoDC cells to the allergens 4-aminophenol, chlorpromazine hydrochloride, 2,4-dinitrochlorobenzene and NiSO 4 also increased surface expression of CD40, while the irritants SDS and benzoic acid were without effect (Coutant et al., 1999). An up-regulation of CD40 was also observed following stimulation of MoDC with the DC maturation stimuli LPS, TNF- and with the contact sensitizer NiSO4 (Arrighi et al., 2001). The use of an alterna tive cytokine cocktail to generate DC from monocytes, namely GM-CSF, IL-4 and TGF- 1, which polarize DC differentiation towards the LC pathway, also showed that $\mathrm{NiSO} 4$ and DNCB induced the up-regulation of molecules involved in antigen pre sentation, namely CD40 (Staquet et al., 2004). Furthermore, treatment of the human myeloid cell line MUTZ-3 with moder ate or strong/extreme sensitizers also up-regulates CD86, CD54, CD40, and B7-H1 in a dose-dependent manner (Azam et al., 2006). Taking together, the results obtained using different LC like cell models highlight the CD40 co-stimulatory molecule as a maturation marker. 
Previous reports showed the pivotal role of CD40-CD40 lig and interactions in the initiation of acquired antigen-specific T-cell mediated immunity. CD40 activation by its ligand is critical for maintaining DC viability, to promote their matu ration through up-regulation of adhesion and co-stimulatory molecules, which enhances T-cell stimulatory capacity, and to control their migration to the draining lymph nodes (Cella et al., 1996; Moodycliffe et al., 2000). The CD40-CD40L inter action also activates cytokine expression in $\mathrm{DC}$ and promotes IL-6 and IL-12 secretion, which are important in driving T-cell response (Mann et al., 2002; Wesa and Galy, 2002). Moreover, ex vivo experiments showed that CD40 is up-regulated in LC isolated from mice sensitized with trinitrochlorobenzene (Aiba, 1998). Therefore, CD40 could be regarded as a marker of DC activation, which is in agreement with our results obtained in the FSDC cell line showing that only skin sensitizers increased CD40 protein levels. Reinforcing this idea, we found that DCNB, the inactive structural analogue of DNFB, had no significant effect on the CD40 protein levels, while the irritants SDS and $\mathrm{BC}$ down-regulate this co-stimulatory molecule (Fig. 4).

In summary, we observed that exposure of FSDC to three dif ferent sensitizers increased the CXCR4 and CD40 protein levels, whereas the irritants, SDS and BC, caused the opposite effect. Therefore, their evaluation may constitute a useful parameter for discriminating between sensitizers and irritants. The increase of CXCR4 protein caused by the sensitizer PPD was also observed in MoDC. Furthermore, our data suggest that evaluation of the total CXCR4 protein levels is more reliable than the analysis of surface expression, since the receptor appears to be internal ized in the presence of maturation stimuli and recycled to the membrane in a later phase. Finally, the use of the FSDC cell line as a LC-like cell model may represent a useful tool in a future in vitro test for sensitizing assessment. We are now evaluating other chemicals and DC maturation markers in FSDC, in order to extend the data about their capacities to discriminate between skin sensitizers and irritants.

\section{Acknowledgements}

We thank Dr. G. Girolomoni (Laboratory of Immunol ogy, Instituto Dermopatico dell'Immacolata, IRCCS, Rome, Italy) for the kind gift of the fetal skin-derived dendritic cell line (FSDC). This work was supported by FCT fellowship (SFRH/BD/30563/2006), and FEDER (Portugal).

\section{References}

Aiba, S., Terunuma, A., Manome, H., Tagami, H., 1997. Dendritic cells dif ferently respond to haptens and irritants by their production of cytokines and expression of co-stimulatory molecules. Eur. J. Immunol. 27, 3031 3038 .

Aiba, S., 1998. Maturation of dendritic cells induced by cytokines and haptens. Tohoku J. Exp. Med. 184, 159-172.

Arrighi, J.F., Rebsamen, M., Rousset, F., Kindler, V , Hauser, C., 2001. A critical role for p38 mitogen-activated protein kinase in the maturation of human blood-derived dendritic cells induced by lipopolysaccharide, TNF-alpha, and contact sensitizers. J. Immunol. 166, 3837-3845.

Ashikaga, T., Hoya, M., Itagaki, H., Katsumura, Y, Aiba, S., 2002. Evaluation of CD86 expression and MHC class II molecule internalization in THP 1human monocyte cells as predictive endpoints for contact sensitizers Toxicol. In Vitro 16, 711-716.

Azam, P., Peiffer, J.L., Chamousset, D., Tissier, M.H., Bonnet, P.A., Vian, L., Fabre, I., Ourlin, J.C., 2006. The cytokine-dependent MUTZ-3 cell line as an in vitro model for the screening of contact sensitizers. Toxicol. Appl. Pharmacol. 212, 14-23.

Banchereau, J., Briere, F., Caux, C., Davoust, J., Lebecque, S., Liu, Y J., Pulen dran, B., Palucka, K., 2000. Immunobiology of dendritic cells. Annu. Rev. Immunol. 18, 767-811.

Basketter, D.A., Pease, C., Kasting, G., Kimber, I., Casati, S., Cronin, M., Diem beck, W., Gerberick, G.F., Hadgraft, J., Hartung, T., Marty, J.P., Nikolaidis, E., Patlewicz, G., Roberts, D., Roggen, E., Rovida, C., van de Sandt, J., 2007.Skin sensitisation and epidermal disposition: the relevance of epider mal disposition for sensitisation hazard identification and risk assessment. The report and recommendations of ECVAM workshop 59. ATLA 351, 137-154.

Becker, D., Kuhn, U., Lempertz, U., Enk, A., Saloga, J., Knop, J., 1997. Flow cytometric screening for the modulation of receptor-mediated endocytosis in human dendritic cells: implications for the development of an in vitro technique for predictive testing of contact sensitizers. J. Immunol. Methods 203,171-180.

Buehler, E.V , 1965. Delayed contact hypersensitivity in the Guinea pig. Arch. Dermatol. 91, 171-177

Cella, M., Scheidegger, D., Palmer-Lehmann, K., Lane, P., Lanzavecchia, A., Alber, G., 1996. Ligation of CD40 on dendritic cells triggers production of high levels of interleukin-12 and enhances T cell stimulatory capacity: T-T help via APC activation. J. Exp. Med. 184, 747-752.

Coutant, K.D., de Fraissinette, A.B., Cordier, A., Ulrich, P., 1999. Modulation of the activity of human monocyte-derived dendritic cells by chemical hap tens, a metal allergen, and a staphylococcal superantigen. Toxicol. Sci. 52, 189-198.

Cruz, M.T., Goncalo, M., Paiva, A., Morgado, J.M., Figueiredo, A., Duarte, C.B., Lopes, M.C., 2005. Contact sensitizers downregulate the expression of the chemokine receptors CCR6 and CXCR4 in a skin dendritic cell line. Arch. Dermatol. Res. 297, 43-47.

Divkovic, M., Pease, C.K., Gerberick, G.F., Basketter, D.A., 2005. Hapten protein binding: from theory to practical application in the in vitro prediction of skin sensitization. Contact Dermat. 53, 189-200.

Ebner, S., Lenz, A., Reider, D., Fritsch, P., Schuler, G., Romani, N., 1998. Expression of maturation-/migration-related molecules on human dendritic cells from blood and skin. Immunobiology 198, 568-587.

EC 2003. 2003/15/EC. Commission Directive of 27 February 2003 amending Council Directive 76/768/EEC on the approximation of laws of the Member States relating to cosmetic products. Off. J. Eur. Union L66, 26-35.

Egan, B.S., Abdolrasulnia, R., Shepherd, VL., 2004. IL-4 modulates transcrip tional control of the mannose receptor in mouse FSDC dendritic cells. Arch. Biochem. Biophys. 428, 119-130.

Gildea, L.A., Ryan, C.A., Foertsch, L.M., Kennedy, J.M., Dearman, R.J., Kim ber, I., Gerberick, G.F., 2006. Identification of gene expression changes induced by chemical allergens in dendritic cells: opportunities for skin sensitization testing. J. Invest. Dermatol. 126, 1813-1822.

Girolomoni, G., Lutz, M.B., Pastore, S., Assmann, C.U., Cavani, A., Ricciard Castagnoli, P., 1995. Establishment of a cell line with features of early dendritic cell precursors from fetal mouse skin. Eur. J. Immunol. 25, 2163-2169.

Herouet, C., Cottin, M., LeClaire, J., Enk, A., Rousset, F., 2000. Contact sen sitizers specifically increase MHC class II expression on murine immature dendritic cells. In Vitro Mol. Toxicol. 13, 113-123.

Hulette, B.C., Ryan, C.A., Gerberick, G.F., 2002. Elucidating changes in surface marker expression of dendritic cells following chemical allergen treatment. Toxicol. Appl. Pharmacol. 182, 226-233.

Hulette, B.C., Ryan, C.A., Gildea, L.A., Gerberick, G.F., 2005. Relationship of CD86 surface marker expression and cytotoxicity on dendritic cells exposed to chemical allergen. Toxicol. Appl. Pharmacol. 209, 159-166.

Humrich, J.Y , Humrich, J.H., Averbeck, M., Thumann, P., Termeer, C., Kamp gen, E., Schuler, G., Jenne, L., 2006. Mature monocyte-derived dendritic cells respond more strongly to CCL19 than to CXCL12: consequences for directional migration. Immunology 117, 238-247. 
Jugde, F., Boissier, C., Rougier-Larzat, N., Corlu, A., Chesne, C., Semana, G., Heresbach, D., 2005. Regulation by allergens of chemokine receptor expression on in vitro-generated dendritic cells. Toxicology 212, 227-238.

Kabashima, K., Sugita, K., Shiraishi, N., Tamamura, H., Fujii, N., Tokura, Y, 2007.CXCR4 engagement promotes dendritic cell survival and maturation. Biochem. Biophys. Res. Commun. 361, 1012-1016.

Kimber, I., Hilton, J., Dearman, R.J., Gerberick, G.F., Ryan, C.A., Basket ter, D.A., Scholes, E.W., Ladics, G.S., Loveless, S.E., House, R.V , et al., 1995.An international evaluation of the murine local lymph node assay and comparison of modified procedures. Toxicology 103, 63-73.

Kuhn, U., Brand, P., Willemsen, J., Jonuleit, H., Enk, A.H., van Brandwijk Petershans, R., Saloga, J., Knop, J., Becker, D., 1998. Induction of tyrosine phosphorylation in human MHC class II-positive antigen-presenting cells by stimulation with contact sensitizers. J. Immunol. 160, 667-673.

Lin, C.L., Suri, R.M., Rahdon, R.A., Austyn, J.M., Roake, J.A., 1998. Den dritic cell chemotaxis and transendothelial migration are induced by distinct chemokines and are regulated on maturation. Eur. J. Immunol. 28, 4114-4122.

Magnusson, B., Kligman, A.M., 1969. The identification of contact allergens by animal assay. The guinea pig maximization test. J. Invest. Dermatol. 52, 268-276.

Mann, J., Oakley, F., Johnson, P.W., Mann, D.A., 2002.CD40 induces interleukin-6 gene transcription in dendritic cells: regulation by TRAF2, AP-1, NF-kappa B, AND CBF1. J. Biol. Chem. 277, 17125-17138.

Matos, T.J., Duarte, C.B., Goncalo, M., Lopes, M.C., 2005. DNFB activates MAPKs and upregulates CD40 in skin-derived dendritic cells. J. Dermatol. Sci. 39, 113-123.

McColl, S.R., 2002. Chemokines and dendritic cells: a crucial alliance. Immunol. Cell Biol. 80, 489-496.

Moodycliffe, A.M., Shreedhar, V , Ullrich, S.E., Walterscheid, J., Bucana, C., Kripke, M.L., Flores-Romo, L., 2000. CD40-CD40 ligand interactions in vivo regulate migration of antigen-bearing dendritic cells from the skin to draining lymph nodes. J. Exp. Med. 191, 2011-2020.

Mosmann, T., 1983. Rapid colorimetric assay for cellular growth and survival: application to proliferation and cytotoxicity assays. J. Immunol. Methods 65,55-63.

Neisius, U., Brand, P., Plochmann, S., Saloga, J., Knop, J., Becker, D., 1999. Detection of increased tyrosine phosphorylation in murine Langerhans cells after stimulation with contact sensitizers. Arch. Dermatol. Res. 291, 22-27.

Ohl, L., Mohaupt, M., Czeloth, N., Hintzen, G., Kiafard, Z., Zwirner, J., Blanken stein, T., Henning, G., Forster, R., 2004. CCR7 governs skin dendritic cell migration under inflammatory and steady-state conditions. Immunity 21 , 279-288.

Pichowski, J.S., Cumberbatch, M., Dearman, R.J., Basketter, D.A., Kimber, I., 2000.Investigation of induced changes in interleukin 1beta mRNA expres sion by cultured human dendritic cells as an in vitro approach to skin sensitization testing. Toxicol. In Vitro 14, 351-360.

Python, F., Goebel, C., Aeby, P., 2007. Assessment of the U937 cell line for the detection of contact allergens. Toxicol. Appl. Pharmacol. 220, 113-124.

Rougier, N., Redziniak, G., Mougin, D., Schmitt, D., Vincent, C., 2000. In vitro evaluation of the sensitization potential of weak contact allergens using langerhans-like dendritic cells and autologous T cells. Toxicology $145,73-82$.
Ryan, C.A., Gerberick, G.F., Gildea, L.A., Hulette, B.C., Betts, C.J., Cumber batch, M., Dearman, R.J., Kimber, I., 2005. Interactions of contact allergens with dendritic cells: opportunities and challenges for the development of novel approaches to hazard assessment. Toxicol. Sci. 88, 4-11.

Ryan, C.A., Gildea, L.A., Hulette, B.C., Dearman, R.J., Kimber, I., Gerberick, G.F., 2004. Gene expression changes in peripheral blood-derived dendritic cells following exposure to a contact allergen. Toxicol. Lett. 150, 301 316.

Ryan, C.A., Kimber, I., Basketter, D.A., Pallardy, M., Gildea, L.A., Gerberick, G.F., 2007. Dendritic cells and skin sensitization: biological roles and uses in hazard identification. Toxicol. Appl. Pharmacol. 221, 384-394.

Sallusto, F., Lanzavecchia, A., 1994. Efficient presentation of soluble antigen by cultured human dendritic cells is maintained by granulocyte/macrophage colony-stimulating factor plus interleukin 4 and downregulated by tumor necrosis factor alpha. J. Exp. Med. 179, 1109-1118.

Sallusto, F., Schaerli, P., Loetscher, P., Schaniel, C., Lenig, D., Mackay, C.R., Qin, S., Lanzavecchia, A., 1998. Rapid and coordinated switch in chemokine receptor expression during dendritic cell maturation. Eur. J. Immunol. 28, 2760-2769.

Schoeters, E., Nuijten, J.M., Van Den Heuvel, R.L., Nelissen, I., Witters, H., Schoeters, G.E., Van Tendeloo, VF., Berneman, Z.N., Verheyen, G.R., 2006. Gene expression signatures in CD34+-progenitor-derived dendritic cells exposed to the chemical contact allergen nickel sulfate. Toxicol. Appl. Pharmacol. 216, 131-149.

Staquet, M.J., Sportouch, M., Jacquet, C., Schmitt, D., Guesnet, J., Peguet Navarro, J., 2004. Moderate skin sensitizers can induce phenotypic changes on in vitro generated dendritic cells. Toxicol. In Vitro 18, 493-500.

Strunk, D., Rappersberger, K., Egger, C., Strobl, H., Kromer, E., Elbe, A., Mau rer, D., Stingl, G., 1996. Generation of human dendritic cells/Langerhans cells from circulating CD34+ hematopoietic progenitor cells. Blood 87, 1292-1302.

Toebak, M.J., Pohlmann, P.R., Sampat-Sardjoepersad, S.C., von Blomberg, B.M., Bruynzeel, D.P., Scheper, R.J., Rustemeyer, T., Gibbs, S., 2006. CXCL8 secretion by dendritic cells predicts contact allergens from irritants. Toxicol. In Vitro 20, 117-124.

Tuschl, H., Kovac, R., Weber, E., 2000. The expression of surface markers on dendritic cells as indicators for the sensitizing potential of chemicals. Toxicol. In Vitro 14, 541-549.

Verhasselt, V., Buelens, C., Willems, F., De Groote, D., Haeffner-Cavaillon, N., Goldman, M., 1997. Bacterial lipopolysaccharide stimulates the production of cytokines and the expression of costimulatory molecules by human periph eral blood dendritic cells: evidence for a soluble CD14-dependent pathway. J. Immunol. 158, 2919-2925.

Vital, A.L., Goncalo, M., Cruz, M.T., Figueiredo, A., Duarte, C.B., Celeste Lopes, M., 2004. The sensitizers nickel sulfate and 2,4-dinitrofluorobenzene increase CD40 and IL-12 receptor expression in a fetal skin dendritic cell line. Biosci. Rep. 24, 191-202.

Wesa, A., Galy, A., 2002. Increased production of pro-inflammatory cytokines and enhanced $\mathrm{T}$ cell responses after activation of human dendritic cells with IL-1 and CD40 ligand. BMC Immunol. 3, 14.

Yoshida, Y., Sakaguchi, H., Ito, Y , Okuda, M., Suzuki, H., 2003. Evaluation of the skin sensitization potential of chemicals using expression of co stimulatory molecules, CD54 and CD86, on the naive THP-1 cell line. Toxicol. In Vitro 17, 221-228. 